\title{
Surface Temperature Inversions in a Canyon
}

\author{
Aylmer H. ThOMPSON ${ }^{1}$ \\ Texas A\&M University, College Station, and National Center for Atmospheric Research, Boulder, Colo.
}

(Manuscript received 19 August 1965, in revised form 5 September 1966)

\begin{abstract}
A micrometeorological investigation was made of ground layer inversion formation, maintenance, and dissipation, and of the related thermal circulations as they were observed in and near the mouth of Red Butte Canyon in the Wasatch Range of northern Utah. Measurements of temperature and other parameters at various locations and levels were made near the mouth of the canyon by means of a semi-automatic instrument and recording network. Analysis of data obtained during the summer of 1957 showed that one basic pattern occurred on 90 per cent of the days. Detailed study of this basic pattern revealed the following significant features:

1) The formation of a thin film of cold air within the canyon an hour or two before (astronomical) sunset.

2) A definite wind shift from up-canyon to down-canyon within about $10 \mathrm{~min}$, near the time of sunset.

3) Extremely rapid local cooling and increase in wind speed near the canyon mouth for about half an hour after the wind shift.

4) Quasi-steady wind and little cooling in the canyon within the first hour after the wind shift, although outside the canyon moderate cooling lasted several hours.
\end{abstract}

\section{Introduction}

Inversions in the atmospheric structure occur frequently throughout most of the world and, where present, usually have considerable influence over local weather. In mountainous areas they are frequently associated with local wind systems. With exceptions such as Young (1921), information on inversions until recently has consisted mostly of quite general studies [see the summaries of Geiger (1965) and Sutton (1953)]. Within the last few years, however, a number of studies have been carried out on various aspects of inversions and local winds (Defant, 1949, 1951; Ekhart, 1949; Fleagle, 1950a, b; Gleeson, 1951). These studies either have dealt with wind and inversion structure under quasi-steady state conditions, or have considered only a single observation point, for (in mountainous terrain) a single cross section 1 of, for example, a canyon. It has seemed desirable to obtain detailed information on the three-dimensional development and structure of inversions in mountain regions as expressed in local wind and temperature changes. The well-defined terrain and relatively confined area of certain mountain canyons facilitate such studies, and the present paper summarizes a study of ground layer inversion formation, maintenance, and dissipation, as observed during summer, in and near the mouth of a canyon in Utah.

\footnotetext{
${ }^{1}$ Formerly affiliated with the University of Utah, Salt Lake City.
}

\section{Observation area and instrumentation}

a) Physiographic setting. Red Butte Canyon, in the Wasatch Range of northern Utah, is a short narrow box canyon located immediately to the NE of Salt Lake City. Oriented nearly NE-SW, it opens to the SW onto a large lake terrace of the Jordan Valley. The stream in the canyon is $5.5 \mathrm{mi}$ in length, and drains an area of $11 \mathrm{mi}^{2}$. The canyon mouth is at $5000 \mathrm{ft} \mathrm{MSL}$, and the head is at $7900 \mathrm{ft}$ MSL.

Fig. 1 is an aerial view, looking ENE, of the canyon and the terrace onto which it opens. The buildings in the foreground are on the University of Utah campus, with Ft. Douglas beyond. Part of the head of the canyon and the upper rim can be seen in cloud shadow at the extreme upper left.

b) Information sources outside the canyon. The U. S. Weather Bureau Station at the Salt Lake City Municipal Airport is located in the Jordan Valley $7 \mathrm{mi}$ directly west of Red Butte Canyon. The standard surface observations taken every half hour at this station were the main source of information on meteorological conditions within the valley, and offered a basis for comparison when the data of the special network set up for the present study were analyzed. Radiosonde observations taken at the airport four times daily provided a sketchy, though extremely valuable, indication of the free-air structure outside the canyon.

c) Micrometeorological network and site descriptions. The micro-study of inversion formation near the mouth 


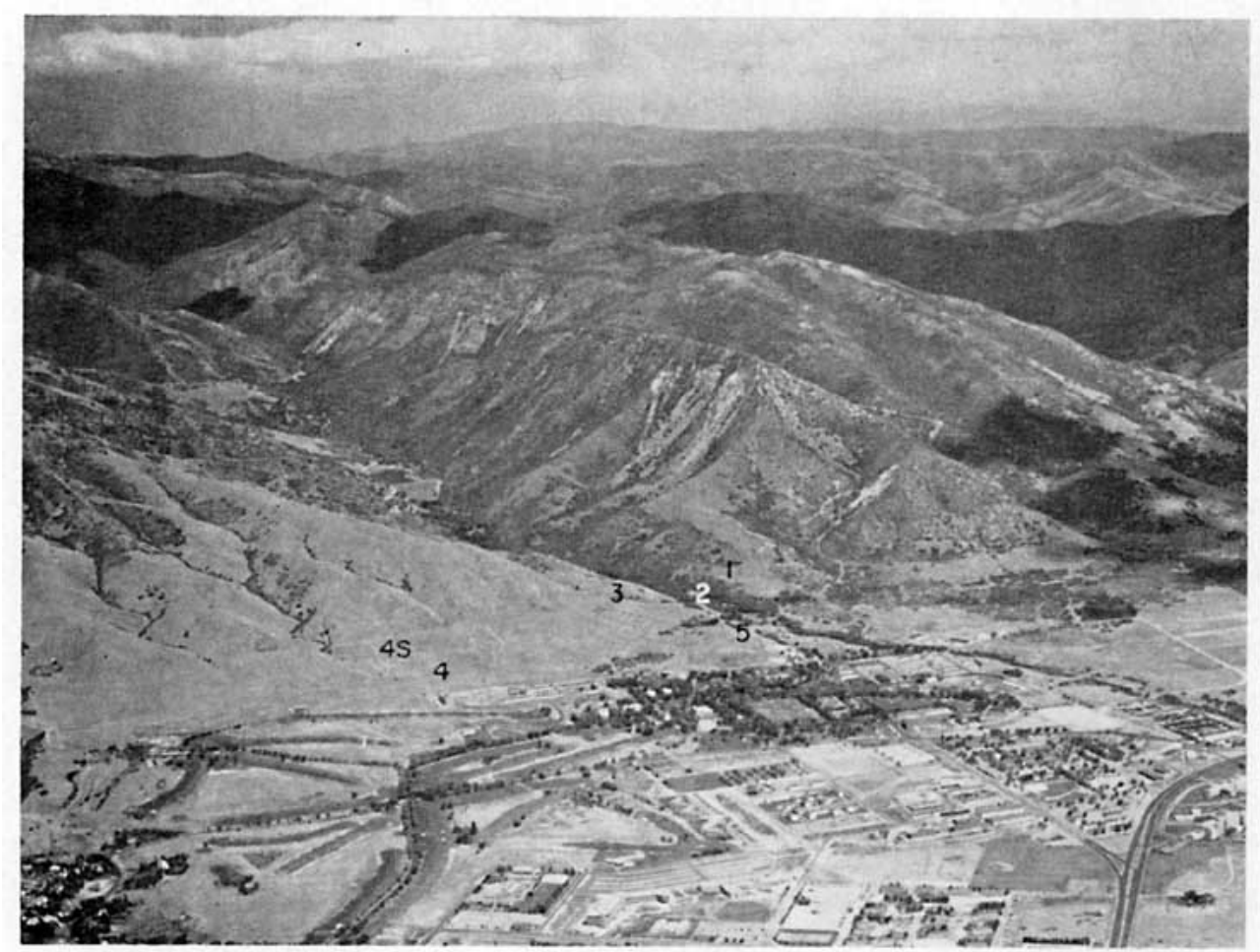

FIG. 1. Aerial photo of Red Butte Canyon, showing by number the observation points in and near the mouth of the canyon.

of the canyon utilized primarily a special network of automatically recording thermometers. Four special thermoshelters and five towers were installed in and near Red Butte Canyon. These sites are located by number on Figs. 1, 5 and 6. A 32-m tower was located next to shelter 2 on the canyon floor about $300 \mathrm{~m}$ upstream from the mouth. Shelters 1 and 3 were located on the southeast and northwest slopes of the canyon, respectively, each at an elevation $30 \mathrm{~m}$ above shelter 2 and also $300 \mathrm{~m}$ upstream from the canyon mouth. Towers $16 \mathrm{~m}$ high were located at each of these shelters. Shelter 4 was located $710 \mathrm{~m}$ northwest of the axis of the canyon on the side of the mountain at the same elevation as Shelter 3. The 16-m tower corresponding to shelter 4 was located down the slope from shelter 4 so that its base was at the same elevation as the base of tower 2. The fifth tower, also $16 \mathrm{~m}$ high, was located within a few meters of the canyon axis and just outside the canyon mouth, $360 \mathrm{~m}$ southwest of, and $10 \mathrm{~m}$ lower than, the base of tower 2 .

The towers were provided with thermopile themometers placed at elevations of $1,2,4,8$ and $16 \mathrm{~m}$ above the ground. Tower 2 also had a thermometer at 32 $m$. Observations from all thermometers were brought by wire to a central location for automatic recording. Measurements were made at all points at intervals of 15 min ( 5 min during periods of rapid change). A wind measuring system was located at the 8-m level on tower 2. A net radiometer was located at the 1-m level on the same tower. During some runs a second radiometer was located at the $16-\mathrm{m}$ level on tower 2 .

Wind and shelter thermograph data were recorded for the entire summer of 1957. The tower network and radiometers were operated on selected days beginning about mid-afternoon and ending about the middle of the following morning.

Fig. 2 shows site 2 and the $32-\mathrm{m}$ tower. The $16-\mathrm{m}$ and 32-m temperature shields are clearly visible against the sky. The radiometer is in position at the 16-m level. The wind equipment can be seen at the 8-m level just to the right of the tower. The truck housed the recording equipment for all towers. The tower and shelter at site 3 are visible on the slope of the canyon in the background.

\section{Observed structure of temperature inversions near the mouth of Red Butte Canyon}

In northern Utah many days during summer are characterized by weak, slowly moving, or stationary pressure systems. Local changes on such days should be determined primarily by local effects. On the night of 24-25 September 1957, the western states were covered by a weak surface high centered in Wyoming, providing an example of the simplest and by far the most common type of nocturnal development observed in and near the canyon. The observed events of this night are examined in some detail and provide a basic 
model of inversion development, maintenance, and dissipation in a small canyon.

Site 2 on the floor of the canyon had wind and radiation measuring equipment in addition to thermometers, and information from these elements will be studied first. Fig. 3 shows wind direction and speed $8 \mathrm{~m}$ above the ground, net radiation $1 \mathrm{~m}$ above the ground, and temperatures at 2, 16 and $32 \mathrm{~m}$ above the ground as functions of time for the night of 24-25 September. Wind from the northeast is directly down the canyon's axis. During the afternoon the wind was up-canyon nearly all the time, the average direction being approximately west-southwest. The direction was quite variable for periods of 2-3 min at various times during the afternoon. During these periods the motion was down the north slope of the canyon. The speed was also variable during the afternoon, but never exceeded $14 \mathrm{mph}$ even in gusts. At 1709 MST the wind, which had been blowing from the west-southwest most of the time for the preceding hour or so, dropped to calm for $8 \mathrm{~min}$. The wind vane indicated up-canyon motion for the first five of these minutes, then shifted abruptly to the down-canyon direction for the remainder of the night. In the next $40 \mathrm{~min}$, the air motion increased to $10 \mathrm{mph}$ average speed, and continued to average that speed for most of the night. The original traces suggest that the shift as well as the earlier variableness took place through northwest, thus from the shady slope of the

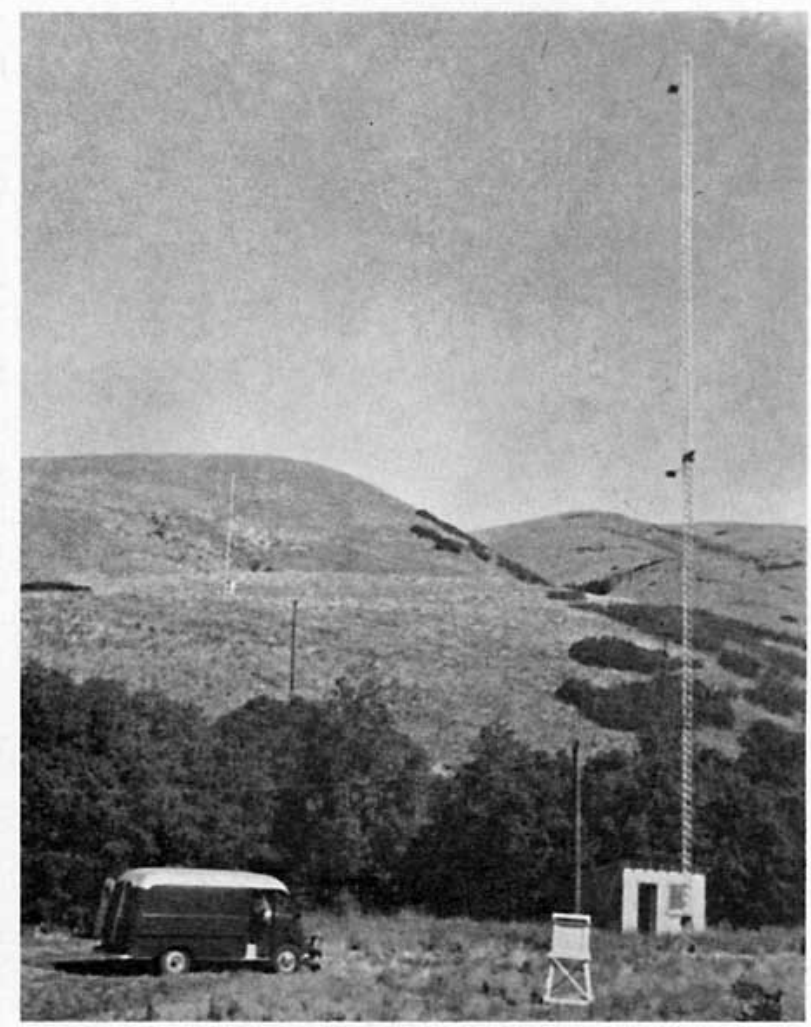

FIG. 2. Site 2 and the truck housing the recorder system. Site 3 is on the hill in the background.

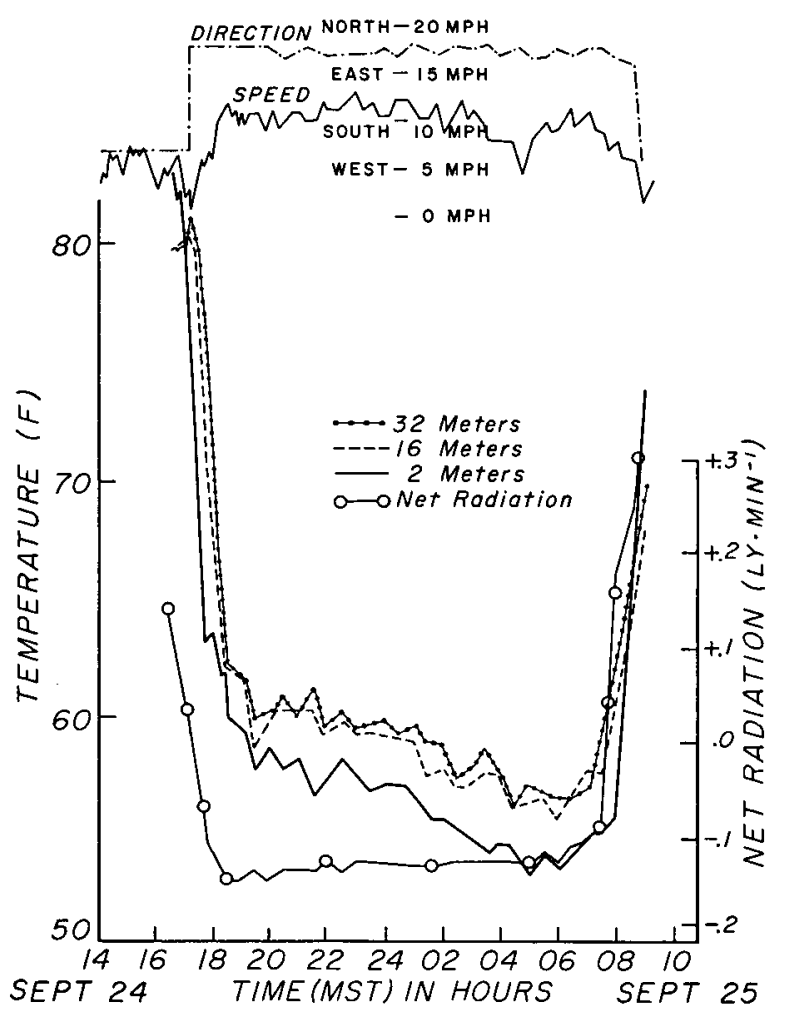

FIG. 3. Data recorded at tower 2, 24-25 September 1957.

canyon. Wind direction also showed little variation during the entire night. Just before 0900 MST the wind shifted back through north to an up-canyon wind, again within only a few minutes.

Net radiation showed a large positive value during the day. As the sun set, the incoming radiation, of course, became quite small while outgoing radiation remained about the same, the net radiation being negative. Net radiation remained nearly constant the entire night, showing only a slight tendency to decrease once the nighttime quasi-equilibrium had been established. At sunrise the following morning, the net radiation again reversed sign.

Fig. 3 also illustrates the temperature changes at selected levels on the tower at site 2 . In the adjacent shelter the temperature remained within about a degree of $80 \mathrm{~F}$ from $1300 \mathrm{MST}$ until the time at which measurements were begun on the tower thermometers. After that time, shelter temperature approximately paralleled the temperature at the $2-\mathrm{m}$ tower level, although it lagged 10-15 min for the first hour of tower operation. Detailed recordings were begun shortly after 1600 MST and at $1630 \mathrm{MST}$ the tower temperatures were fairly close to those measured at the shelter. At 1630 MST a pronounced superadiabatic lapse rate was present between 2 and $16 \mathrm{~m}$ (see also Fig. 6).

Beginning about $1650 \mathrm{MST}$, the temperature dropped quite rapidly, first at the base of tower 2 , then at the shelter, then at the top of the tower, but at each 
position the drop in temperature began 20-40 min before the position became shadowed as the sun set behind the hills. At each position, the temperature required only $40 \mathrm{~min}$ to drop $18 \mathrm{~F}$, a rate of approximately $0.5 \mathrm{~F} \mathrm{~min}^{-1}$. This rate may be compared with a steady fall at the airport of about $18 \mathrm{~F}$ in $2 \frac{1}{2} \mathrm{hr}$ (see Fig. 4). About 1800 MST the cooling rate abruptly changed at all positions, becoming essentially constant (neglecting turbulent fluctuations) at $0.5 \mathrm{~F} \mathrm{hr}^{-1}$ for the remainder of the night. The temperature rose during the first hour or so after sunrise at only about 40 per cent of the rate of fall the previous evening.

Before sunset the usual decrease in temperature with height was clearly evident (see Fig. 3). The normal lapse conditions changed to inversion at the same time that the temperatures at the tower base began falling. The inversion persisted during the entire night. The magnitude of the lapse rate was nearly always more pronounced below the $16-\mathrm{m}$ level than above. The inversions were strongest during the hour of maximum temperature decrease. For the hour commencing at $1705 \mathrm{MST}$, the average temperature difference between 2 and $16 \mathrm{~m}$ was $8.9 \mathrm{~F}$ [equivalent to $35 \mathrm{C}(100 \mathrm{~m})^{-1}$ ]. Over this same period the temperature difference between 16 and $32 \mathrm{~m}$ averaged only $0.7 \mathrm{~F}$. During the remainder of the night, the inversion averaged $2.1 \mathrm{~F}$ between 2 and $16 \mathrm{~m}$ and $0.4 \mathrm{~F}$ between 16 and $32 \mathrm{~m}$,

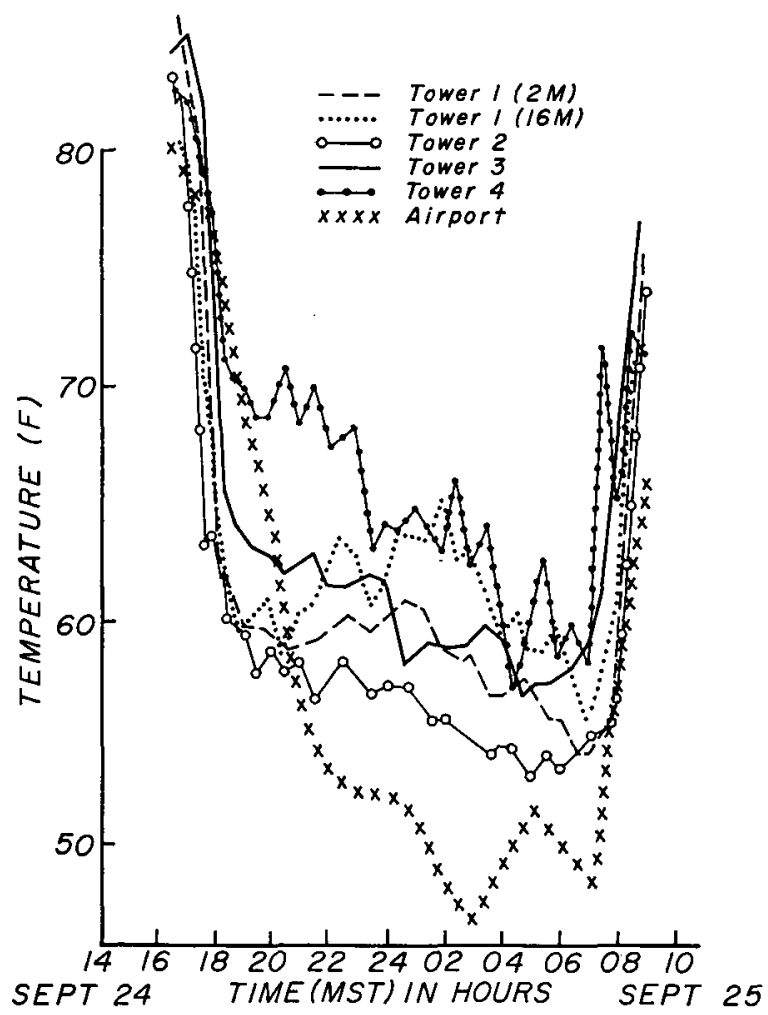

FIG. 4. Temperature at $2 \mathrm{n}$ : above surface at selected stations and at $16 \mathrm{~m}$ at tower $1,24-25$ September 1957. indicating the same type of inversion as the earlier one but of smaller magnitude.

The temperature trends for the other towers are shown by the traces for the 2 -m level only (except both 2- and 16-m levels at tower 1) in Fig. 4. For comparison, the $2-\mathrm{m}$ level for tower 2 is included.

Site $3,30 \mathrm{~m}$ higher on the canyon slope northwest of site 2, showed similar characteristics. The same rapid cooling as at site 2 occurred in the early evening. The strong temperature drop occurred simultaneously at all levels at this tower, in contrast to the situation at site 2 . The time of the drop at site 3 was the same as at the upper levels at site 2 , thus before actual sunset.

The temperature patterns at site 1 showed the same sharp drop after 1730 MST as at the site 2 upper levels, and a drop to the same values as site 2 for nearly three hours, in spite of the fact that site 1 was $30 \mathrm{~m}$ higher on the southeast side of the canyon. The lapse at times was nearly isothermal, or even showed a temperature decrease with height from the 16-m level on tower 2 to the top of tower 1 . Between 2130 and 2200 MST the temperatures at the upper levels of tower 1 rose a few degrees, and an inversion of $2-6 \mathrm{~F}$ formed between 2 and $16 \mathrm{~m}$. The temperature showed pronounced variations from one observation time to the next, but the general trend with time was a slight rise from 2100 to 0200 MST. After 0200 MST the temperature gradually dropped to a minimum at $0700 \mathrm{MS} T$. At sunrise the temperatures rapidly rose, though again not as rapidly as they fell.

At site 5 the pattern was almost identical to that at site 3 , despite its location directly downwind of site 2 and in the canyon mouth, where the air should have been comparatively cool. Hence, this trace is not represented in Fig. 4.

The trend of temperature at site 4 , well away from the canyon, was quite different from trends at all sites within the canyon or even on the valley floor. The initial drop in temperature was less rapid than, and about half the magnitude of, the changes within the canyon, and was followed by nearly steady temperatures until just before midnight. At that time the temperature dropped about $3 \mathrm{~F}$ and then remained relatively steady until 0330 MST. Fluctuations of up to $10 \mathrm{~F}$ occurred for the remainder of the night. The fluctuations were also quite strong as the temperature rose during the morning.

While the drop at midnight was not observed frequently throughout the summer, the drop and fluctuations near sunrise were frequently observed (Brooks and Schultz, 1958; Fleagle, 1950b).

Data from the towers were used to construct a set of maps and cross sections, which showed the threedimensional development, maintenance and dissipation of the inversion within Red Butte Canyon. A given time is represented by a map and three cross sections. The maps show surface contours and locations of the 


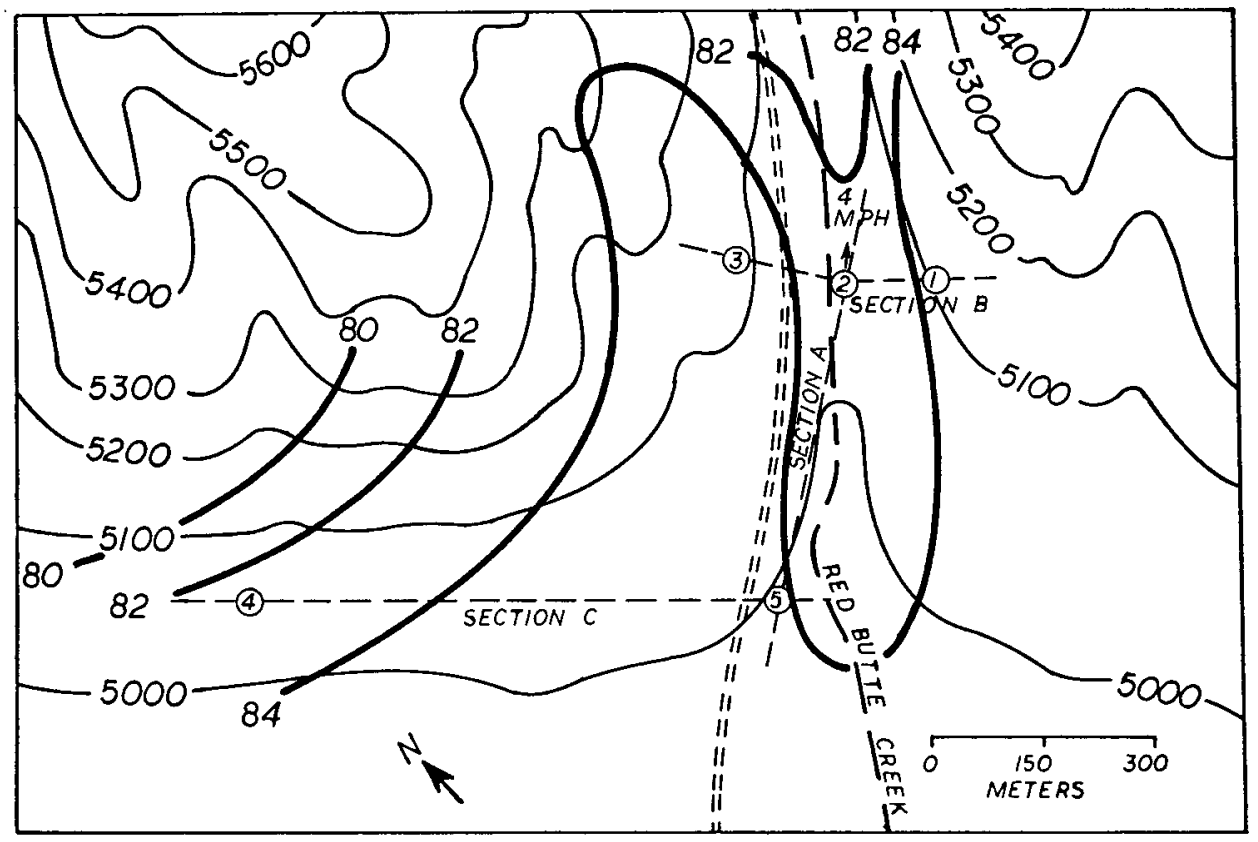

FIG. 5. Temperature distribution $2 \mathrm{~m}$ above the surface at $1635 \mathrm{MST} 24$ September 1957. Instrument sites and locations of cross sections are added. Contour elevation labels are in feet.

various observation sites. The isotherm analyses represent conditions $2 \mathrm{~m}$ above the surface except that the wind at site 2 was measured at the 8 -m level. Fig. 5 is the base map with locations of the three cross sections. The cross sections provide two profiles normal to the canyon axis and one along the axis. Fig. 6 shows a set of analyzed cross sections. Note that the horizontal scales of the various cross sections differ. For the examples discussed here, not all the cross sections are accompanied by maps; when a map is omitted the temperature distribution may be inferred from the appropriate cross sections.

Conditions during the afternoon of 24 September are well represented by the pattern at 1635 MST, shown in Figs. 5 and 6 . The map shows little difference in temperature throughout the area, although the canyon floor and the air directly above the floor appear to be slightly cooler than the sloping walls. The cross sections show the common afternoon features of warm surfaces and superadiabatic lapse rates in the surface layers. All towers showed such lapses below $8 \mathrm{~m}$. At towers 1 and 5 , such conditions extend higher than the tops of the towers. Thus, the atmosphere (at the time) was characterized by superadiabatic lapse rates in the lowest few meters or few tens of meters, above which there was an isothermal or at least relatively stable thin layer. Still higher, the lapse was probably nearly adiabatic.

Within $15 \mathrm{~min}$ after $1635 \mathrm{MST}$ (not illustrated) the floor of the canyon below $4 \mathrm{~m}$ showed definite cooling (base of tower 2), whereas no other point showed any essential change from the conditions of Figs. 5 and 6.
The wind at $8 \mathrm{~m}$ at tower 2 was still definitely up the canyon.

Temperatures at all locations changed only slightly during the $25 \mathrm{~min}$ after $1650 \mathrm{MST}$. In particular, the cold air at the base of tower 2 did not get appreciably colder or deeper. At 1713 MST the wind direction at $8 \mathrm{~m}$ at tower 2 (Fig. 3) shifted from up-canyon to down-canyon. During the next $5 \mathrm{~min}$, pronounced cooling and deepening of the cold air within the canyon took place, as illustrated by Fig. 7. Compare this figure with Figs. 5 and 6, accepting that at 1710 MST conditions were similar to those of Figs. 5 and 6 except for a thin cold film of surface air only 2 or $\dot{3} \mathrm{~m}$ thick near tower 2 on the floor of the canyon. The shapes of the isotherms and their speed of movement down the canyon (though much slower than the speed of the 8-m wind at tower 2) suggest almost a "frontal passage."

At 1740 MST (Figs. 8 and 9), the cold air within the canyon had reached at least to tower 5 , and probably a short distance beyond, as suggested by the 2-m map. At tower 2 the cold air was only about $16 \mathrm{~m}$ deep. It appeared deeper on the southeast side of the canyon than on the northwest side. The map and the cross sections all suggest a "front" or a "river" of air forming in the canyon and flowing out of the canyon, but the analogy is not complete. Note also the cross section from tower 4 to tower 5 . The air on the slope away from the canyon was still warm; the warm air extended above the influx of cold air from the canyon at the base of tower 5 . The irregular lapse rates at the base of tower 5 were particularly pronounced at this time. At first they 


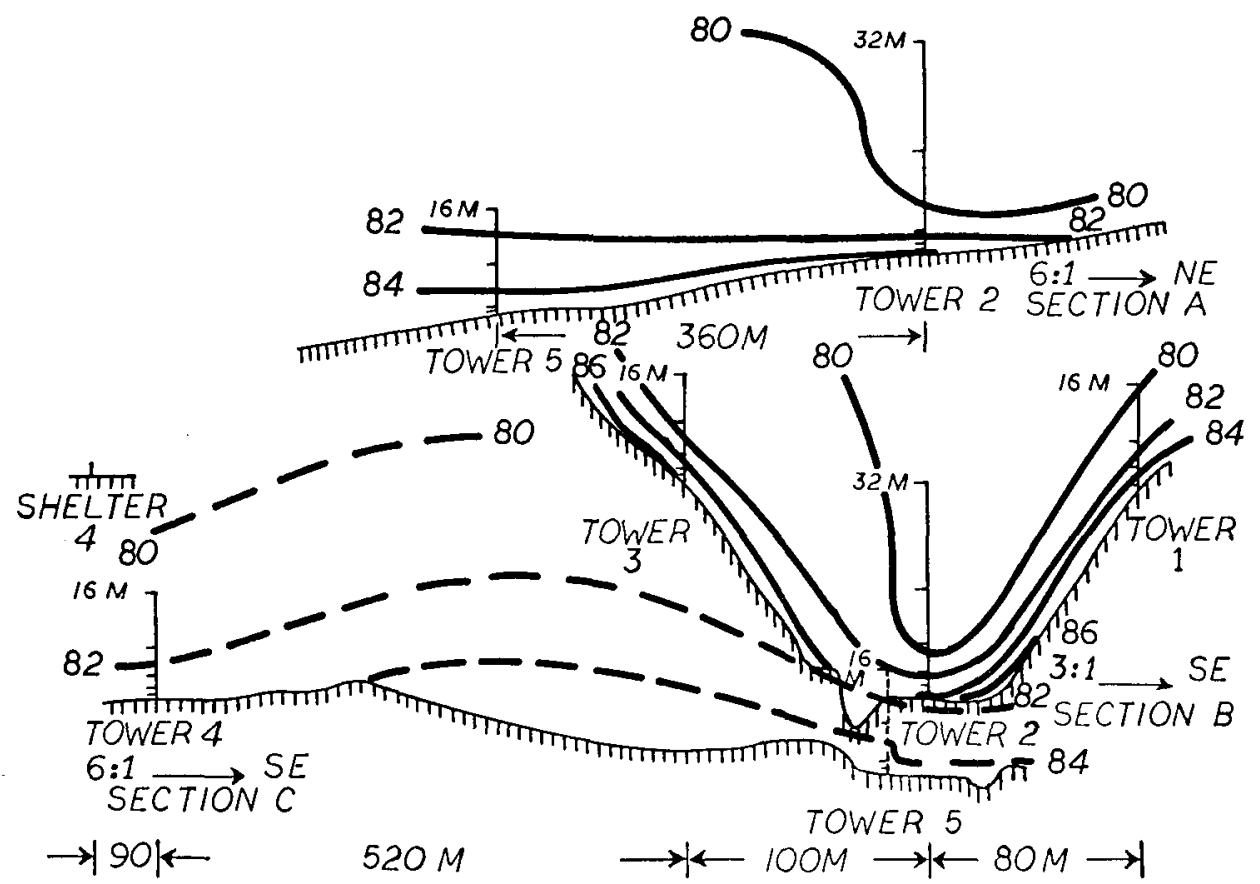

FIG. 6. Temperature profiles for 1635 MST 24 September 1957. Note: On this and all the following profiles the solid lines are for sections " $\mathrm{A}$ " and " $\mathrm{B}$ " and the dashed lines are for section " $\mathrm{C}$," which should be considered as being $360 \mathrm{~m}$ in front of section "B." The horizontal scales differ. See Fig. 5.

were believed due to instrument error. However, since they were not present at all times, although they were present on other nights, the conclusion is that they were due to some undetermined local influence.

From 1740 to 1800 MST the cold air rapidly deepened and spread outward toward the valley. The strong temperature gradients were lifted out of the region of the measurements within and downwind of the canyon. A strong gradient still existed between tower 4 and the observation points within the canyon.

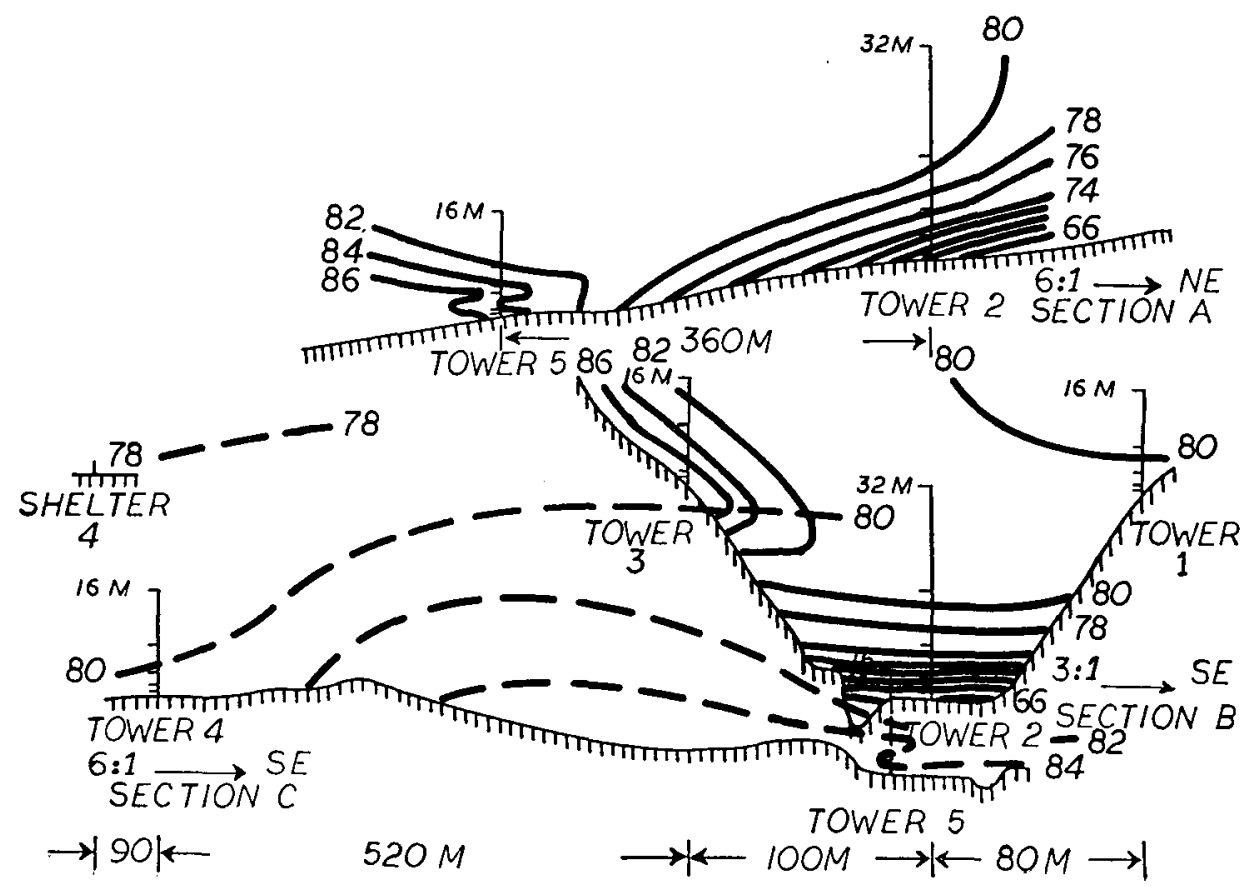

Fịg. 7. Temperature profiles for 1720 MST 24 September. 1957. 


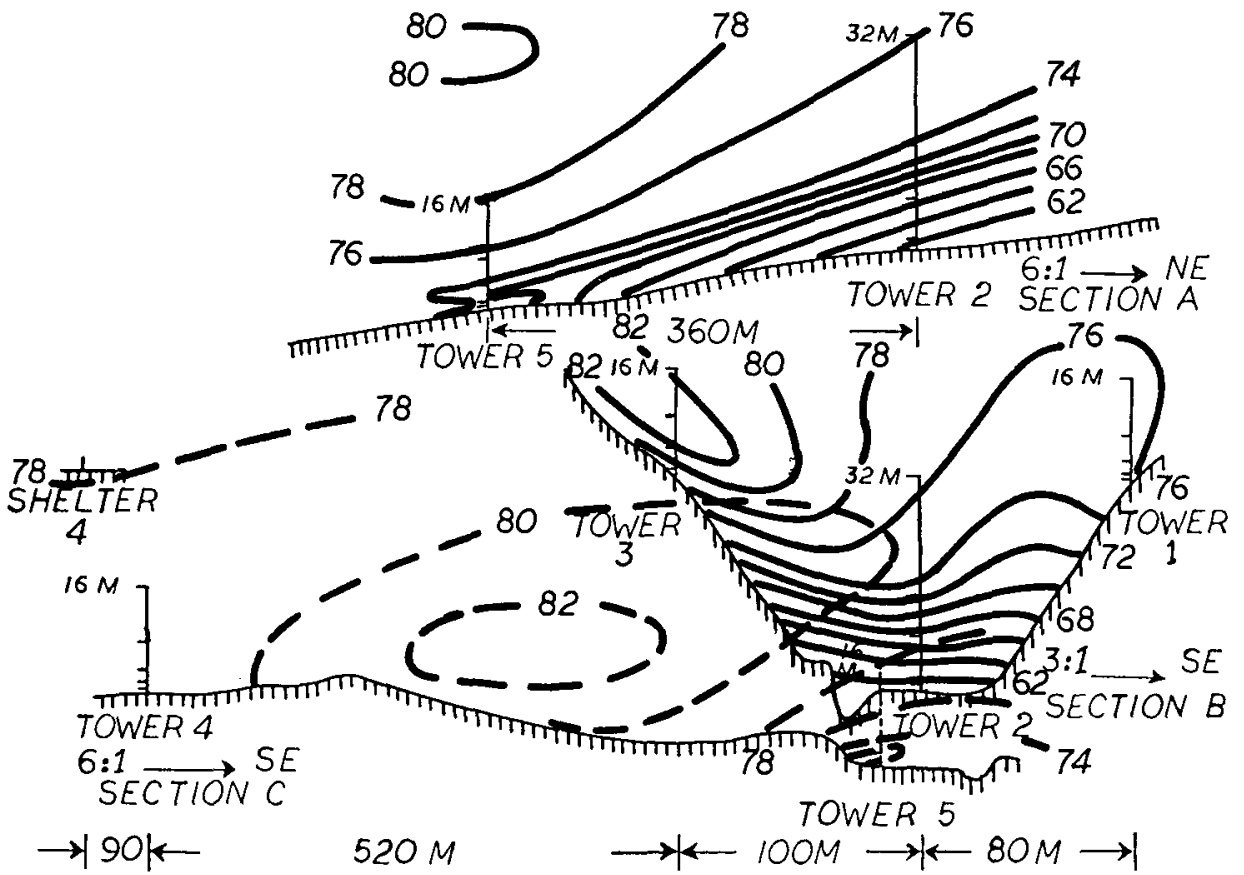

FIG. 8. Temperature profiles for 1740 MST 24 September 1957.

By 1900 MST, the gradient between tower 4 and the canyon had materially decreased, since the air on the slopes cooled much more rapidly during this hour than did the air flowing down the canyon (Fig. 10). No quantitative measurements of wind were made, but subjective observations made while traveling from tower to tower suggested that, during the evening, air moved down the slopes near tower 4 nearly as rapidly as it was moving in the canyon. Further, the air at towers 1 and 3 was moving parallel to the canyon axis. The fall in temperature on the northwest slope of the canyon was less than on the southeast slope, producing quite irregular isotherms within the canyon.

During the next few hours there was little change except gradual cooling. By 2215 MST (Fig. 11) air temperatures over the northwest and southeast slopes

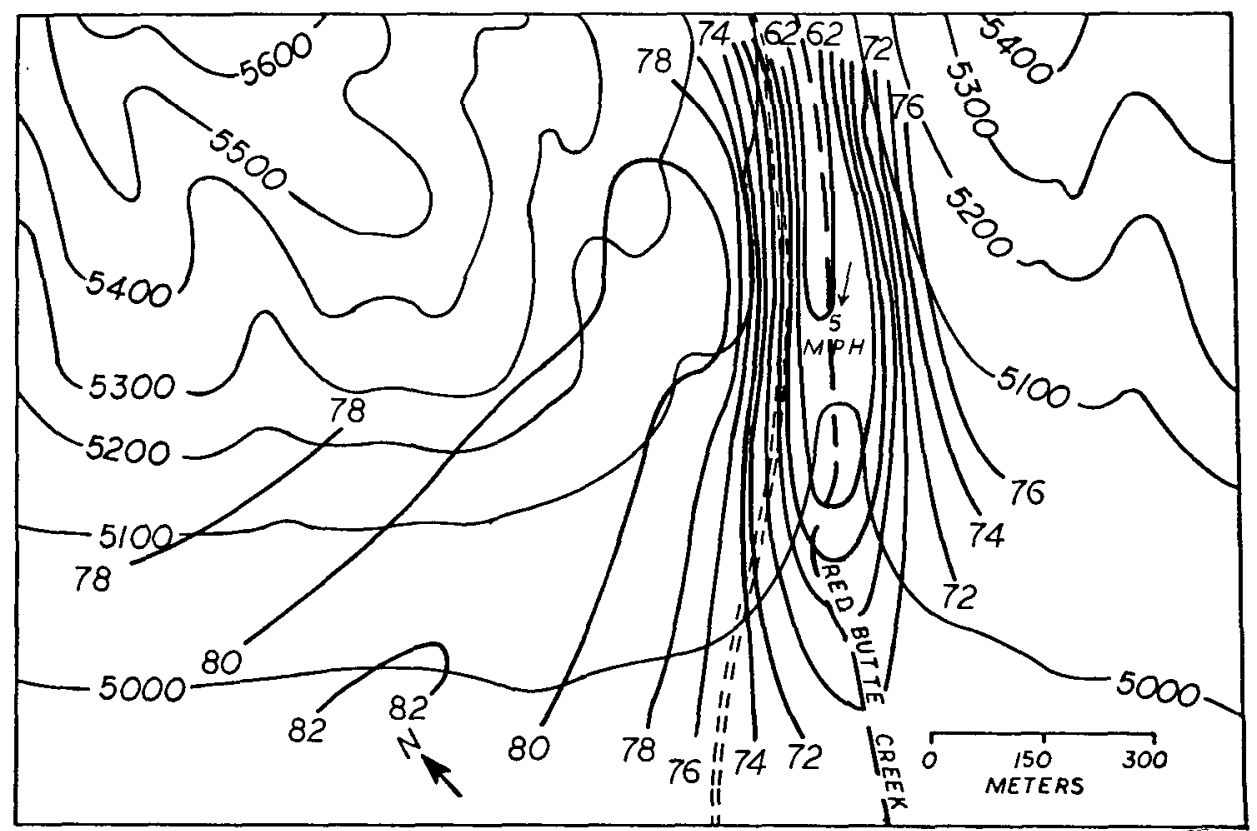

Fig. 9. Temperature distrịbution 2_m above the surface at 1740 MST 24 September 1957. 


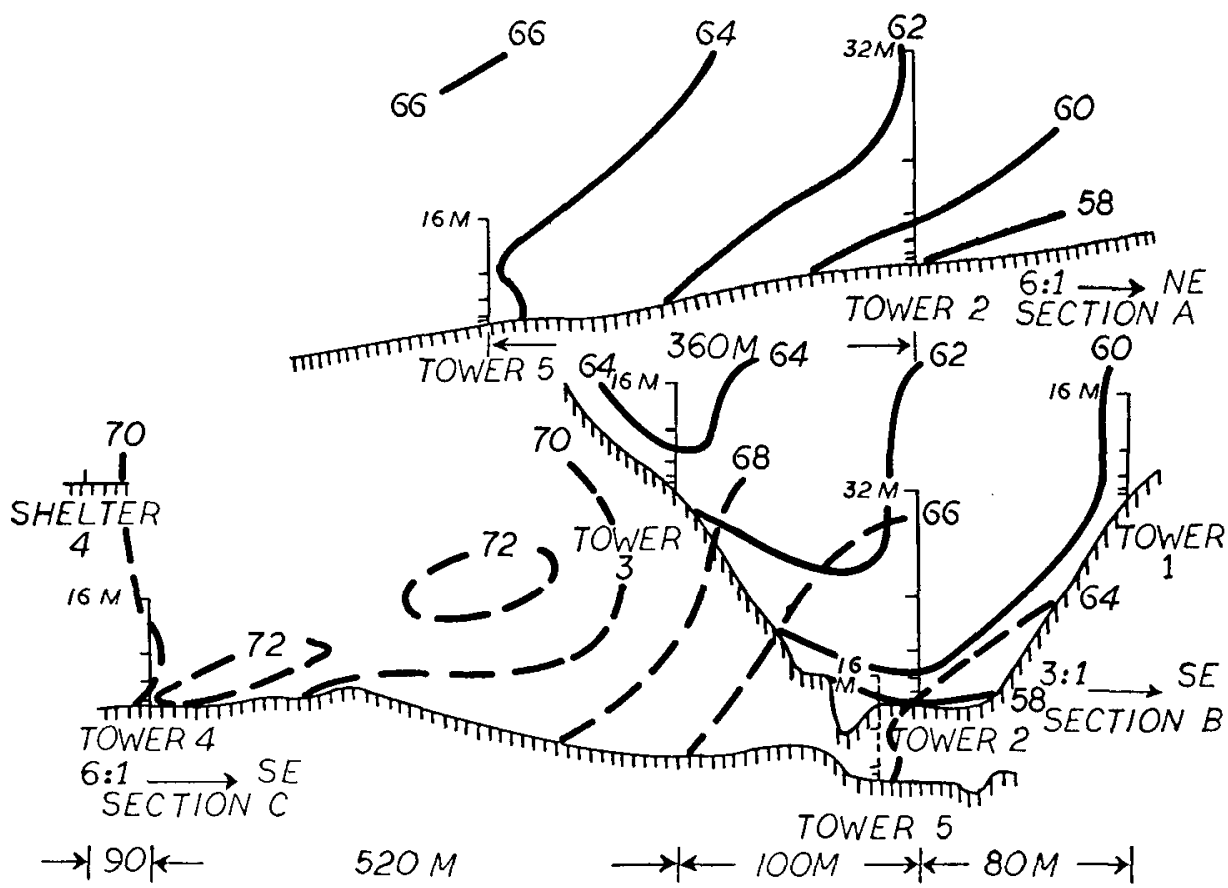

FIG. 10. Temperature profiles for 1900 MST 24 September 1957.

were nearly the same. The air above the canyon floor was about the same temperature as, or slightly warmer than, the air at the same level on the slope. This condition persisted for most of the remainder of the night, as shown in Fig. 12 for 0500 MST. By 0500 the two slopes had about the same air temperature, the 0500 MST sections showing the isotherms to be nearly parallel to the canyon floor in the direction of the long axis and nearly horizontal in the direction normal to this axis.

Warming started on the northwest slope about 0700 MST. During the next hour the wind remained downcanyon but gradually dropped in speed. At 0850 MST it was nearly calm, but still definitely down-canyon. At

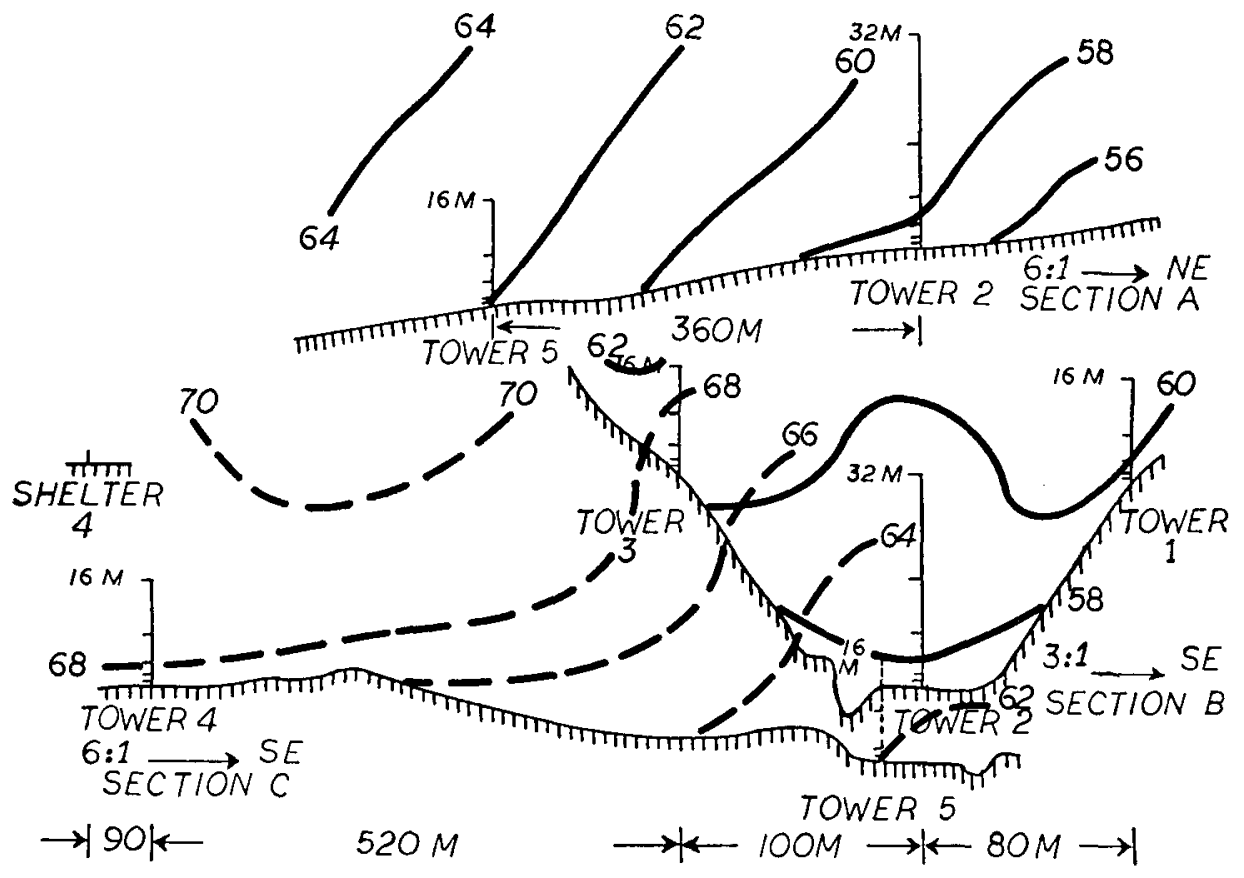

FIG. 11. Temperature profiles for 2215 MST 24 September 1957. 


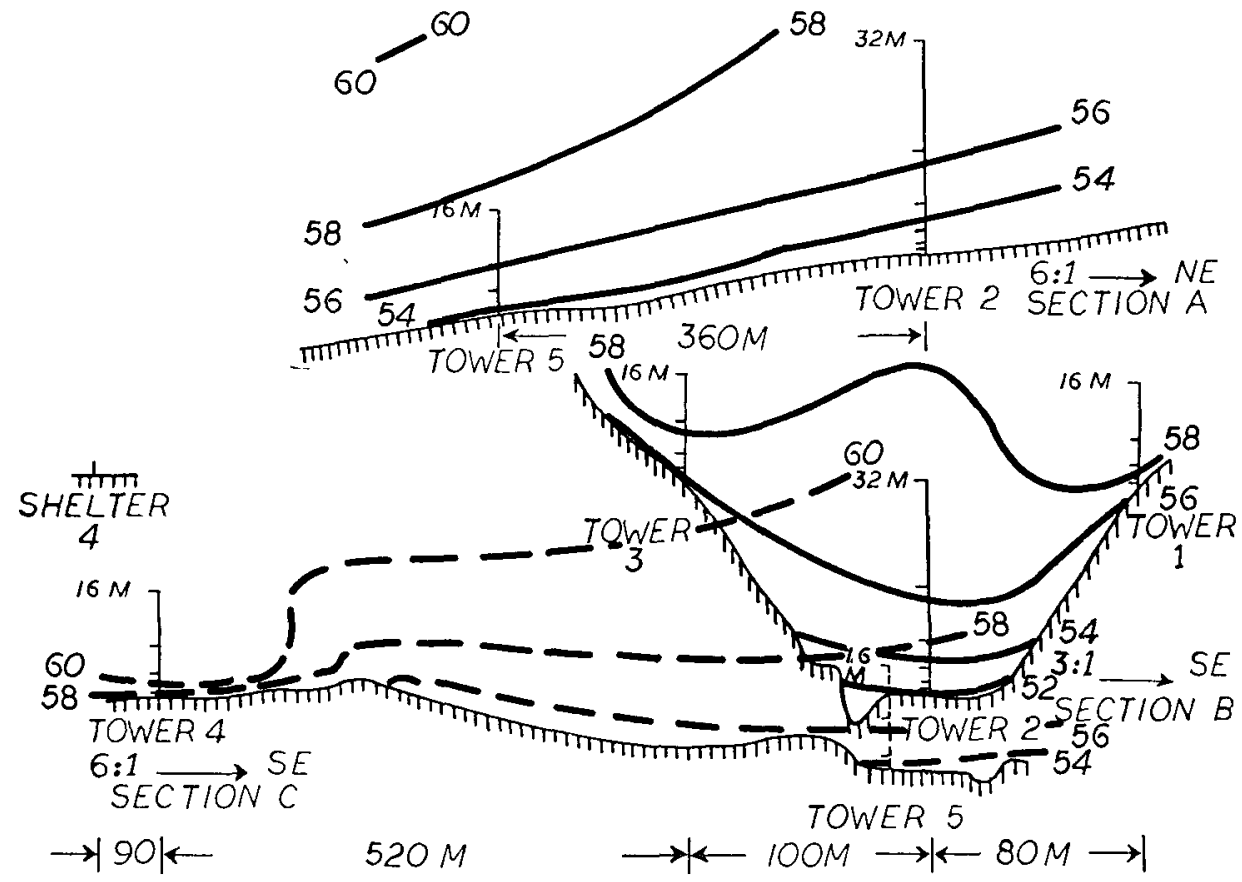

FIG. 12. Temperature profiles for 0500 MST 25 September 1957.

0855 MST the wind abruptly shifted $180 \mathrm{deg}$ and remained thus for several hours, with little variation.

By 0900 MST all stations showed strong superadiabatic lapse rates and rapid warming, as illustrated in Fig. 13. The canyon floor was colder than either slope, though not as cold as the slope near tower 4 .
The most pronounced feature was the core of cold air extending in cross section from a short way up the southeast slope into the middle of the canyon. The longitudinal sections suggest that this cold air did not extend below the canyon mouth but probably did extend up-canyon. Fifteen minutes later (not illus-

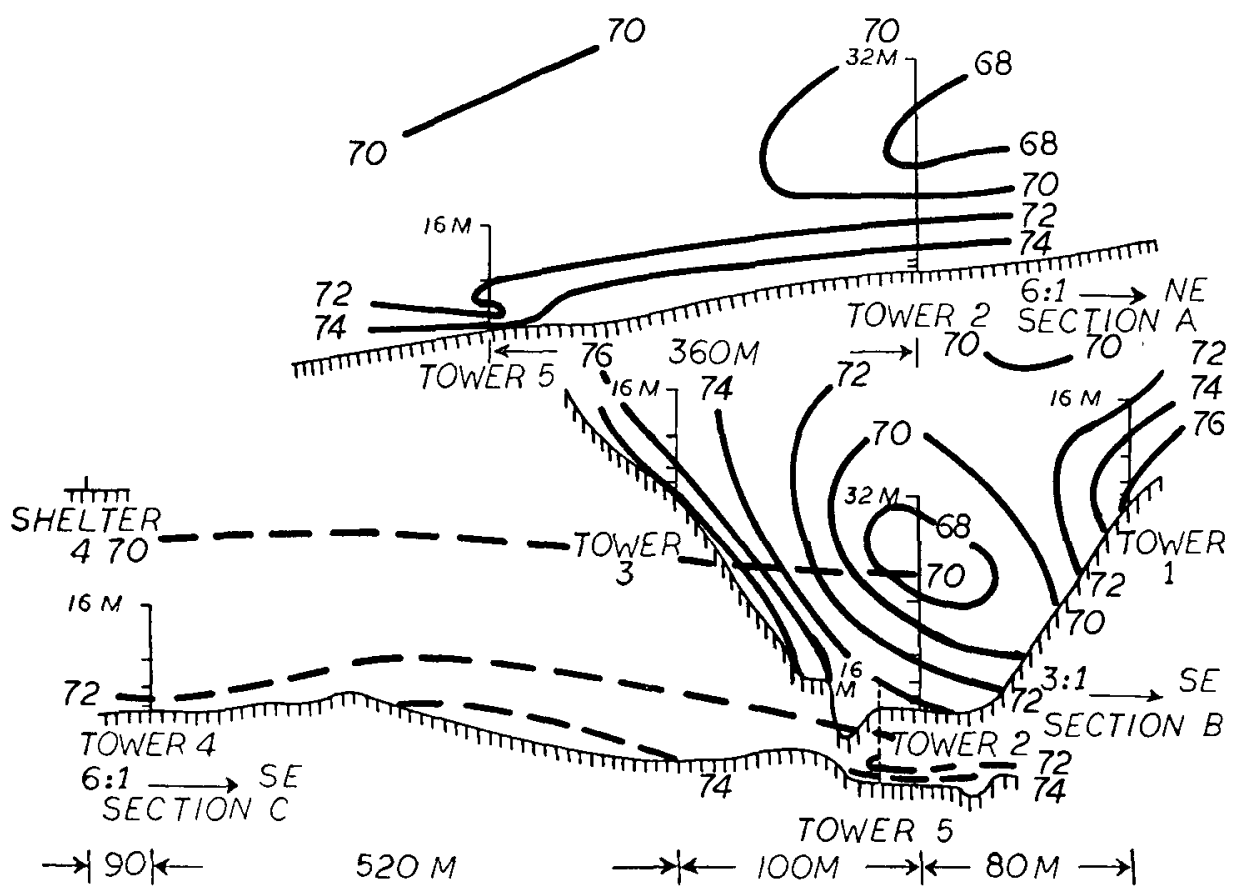

FIG. 13. Temperature profiles for 0900 MST 25 September 1957. 
trated) the volume of cold air had risen above the tops of the towers.

\section{Summary}

The main features of the temperature and wind behavior patterns observed the night 24-25 September 1957, and also most other nights of that summer, were:

1) Formation of a thin film of cold air on the floor of the canyon and possibly a short distance up the canyon slopes. This film must have been present much earlier in shaded areas further up the canyon (Fig. 7).

2) Rapid wind shift from up-canyon to down-canyon wind. Wind direction varied markedly before the downward flow established itself, but changed little thereafter (Fig. 3).

3) Extremely rapid cooling within the canyon during the first hour of down-canyon wind. The full development seemed to be reached within the hour. Cooling outside the canyon was slower (Figs. 3 and 4 ).

4) Rapidly increasing wind speed accompanying the cooling, followed by steady or slightly decreasing wind the remainder of the night (Fig. 3).

5) Slight cooling within the canyon after the first hour. Moderate cooling continued outside the canyon for several hours (Figs. 3 and 4).

6) Presence of a core of cold air in the canyon as morning heating progressed (Fig. 13).

7) Rapid wind shift from down-canyon to up-canyon in the morning.

\section{Other types of developments}

A variation of the basic pattern described in the preceding paragraphs involved a temporary rapid warming at one or more of the towers after the nighttime regime had apparently become well established. Some indication of such warming is shown by the data of tower 1 (Fig. 4), where the temperature rose for several hours after about $2000 \mathrm{MST}$, although it was falling at the other locations. On some nights the rise occurred at several locations and amounted to as much as $12-15 \mathrm{~F}$, usually accompanied by an increase in the inversion intensity. Although wind data were insufficient to allow definite conclusions, it appeared most likely that such events were associated with a divergence in the mouth of the canyon, or with air flow across the canyon axis, or both. On the night of 24-25 September the gradient wind near the surface was across the canyon from the southeast through south, suggesting the possibility of the latter effect.
In all other respects, the events of such nights were similar to those described in the preceding section.

On 90 per cent of the days of the summer observation period, the inversion followed the basic pattern or its variation described above. On the remainder of the days weather conditions were disturbed by nearby fronts or instability and thunderstorms.

\section{Application to other areas}

Most other studies (Defant, 1951; Ekhart 1949; Young, 1921) were made in much larger valleys, comparable to the valley into which Red Butte Canyon opens. The important difference in events is probably the earlier and more rapid development in the smaller canyon. Otherwise, the events are similar, though lack of detail in the studies of the larger valleys does not allow exact comparison. It thus appears probable that the inversion development described is representative of most small canyons.

Acknowledgments. The Quartermaster Engineering and Research Command, through Contract DA 19-129QM-399 with the University of Utah, provided financial assistance for the construction of the observation net and for making the observations. Grateful appreciation is expressed to the many colleagues who were willing to discuss constructively my activities in making this investigation.

The final version of the manuscript was prepared while the writer was participating in the Summer Visitor Program at the National Center for Atmospheric Research.

\section{REFERENTES}

Brooks, F. A., and H. B. Schultz, 1958: Observations and interpretation of nocturnal density currents. Proc. Canberra Symposium, Arid Zone Research, UNESCO, 272-277.

Defant, F., 1949 : Zur Theorie der Hangwinde, nebst Bemerkungen zur Theorie der Berg- und Talwinde. Arch. Meteor. Geophys. Bioklimatol., A1, 421-450.

—, 1951: Local winds. Compendium of Meteorology, Boston, Amer. Meteor. Soc., 655-672.

Ekhart, E., 1949: Uber Inversionen in den Alpen. Meteor. Rund., 2, $152-159$.

Fleagle, R. G., 1950a: A theory of air drainage. J. Meteor., 7, 227-232.

_- 1950b: Radiation theory of local temperature differences. J. Meteor., 7, 114-120.

Geiger, R., 1965: The Climate Near the Ground. Revised Edition, Cambridge, Mass., Harvard University Press, 611 pp.

Gleeson, T. A., 1951: On the theory of cross-valley winds arising from differential heating of the slopes. J. Meteor., 8, 398-405.

Sutton, O. G., 1953: Micrometeorology. New York, McGrawHill, Inc., 323 pp.

Young, F. D., 1921: Nocturnal temperature inversions in Oregon and California. Mon. Wea. Rev., 49, 138-148. 